OPEN ACCESS

Edited by:

Anahid Jewett,

University of California, Los Angeles,

United States

Reviewed by:

Zong Sheng Guo,

University of Pittsburgh, United States

William L. Redmond,

Earle A. Chiles Research

Institute, United States

${ }^{*}$ Correspondence:

Jennifer $D$. Wu

jennifer.wu@northwestern.edu

Specialty section:

This article was submitted to

Cancer Immunity and Immunotherapy,

a section of the journal

Frontiers in Oncology

Received: 25 June 2019

Accepted: 27 August 2019

Published: 11 September 2019

Citation:

Boettcher AN, Usman A, Morgans A,

VanderWeele DJ, Sosman J and

Wu JD (2019) Past, Current, and

Future of Immunotherapies for

Prostate Cancer. Front. Oncol. 9:884.

doi: 10.3389/fonc.2019.00884

\section{Past, Current, and Future of Immunotherapies for Prostate Cancer}

\author{
Adeline N. Boettcher ${ }^{1}$, Ahmed Usman ${ }^{2}$, Alicia Morgans ${ }^{2}$, David J. VanderWeele ${ }^{2}$, \\ Jeffrey Sosman ${ }^{2}$ and Jennifer $D$. W $u^{1,3 *}$
}

${ }^{1}$ Department of Urology, Feinberg School of Medicine, Northwestern University, Chicago, IL, United States, ${ }^{2}$ Department of Hematology and Oncology, Feinberg School of Medicine, Northwestern University, Chicago, IL, United States, ${ }^{3}$ Department of Microbiology and Immunology, Feinberg School of Medicine, Northwestern University, Chicago, IL, United States

Prostate cancer $(\mathrm{PCa})$ is the most common cancer in men, and the second leading cause of cancer related death in men in Western countries. The standard therapy for metastatic PCa is androgen suppression therapy (AST). Men undergoing AST eventually develop metastatic castration-resistant prostate cancer (mCRPC), of which there are limited treatment options available. Immunotherapy has presented substantial benefits for many types of cancer, but only a marginal benefit for mCRPC, at least in part, due to the immunosuppressive tumor microenvironment (TME). Current clinical trials are investigating monotherapies or combination therapies involving adoptive cellular therapy, viral, DNA vaccines, oncolytic viruses, and immune checkpoint inhibitors $(\mathrm{ICl})$. Immunotherapies are also being combined with chemotherapy, radiation, and AST. Additionally, preclinical investigations show promise with the recent description of alternative ways to circumvent the immunosuppressive nature of the prostate tumor microenvironment, including harnessing the immune stimulatory NKG2D pathway, inhibiting myeloid derived suppressor cells, and utilizing immunomodulatory oncolytic viruses. Herein we provide an overview of recent preclinical and clinical developments in cancer immunotherapies and discuss the perspectives for future immunotherapies in $\mathrm{PCa}$.

Keywords: prostate cancer, metastatic-castration resistant prostate cancer, immunotherapy, combination therapy, immune checkpoint inhibitor

\section{INTRODUCTION}

Prostate cancer $(\mathrm{PCa})$ is the most commonly diagnosed malignancy and ranked the second leading cause of cancer related death in US men (1). Radical prostatectomy and/or radiation are the standard primary treatments for patients with localized PCa, while recurrent disease and/or advanced staged PCa, the main therapy is androgen ablation (2) with or without therapy intensification. Despite initial effective responses with androgen suppression therapy (AST), almost all patients ultimately progress to metastatic castration-resistant prostate cancer (mCRPC) (3). Docetaxel, abiraterone, enzalutamide, cabazitaxel, and Sipuleucel-T (Sip-T) (4-9) are approved by the FDA for the treatment of mCRPC, however each of these regimens provides only limited 2-4 months median survival benefit. The median overall survival (OS) for mCRPC patients ranges from 13-32 months with a 15\% 5-year survival rate $(10,11)$. Therefore, efforts to explore new therapeutic modalities for mCRPC are urgently needed. 
In the last decade there have been significant milestones achieved for immunotherapies. In 2010, the FDA approved the first dendritic cell based vaccine, Sip- $\mathrm{T}$ for the treatment of non-symptomatic metastatic prostate cancer (9). Following this approval, the immune checkpoint CTLA- 4 inhibitor, ipilimumab, was approved for the treatment of metastatic melanoma in 2011 (12). Shortly thereafter, immune checkpoint PD-1/PD$1 \mathrm{~L}$ inhibitors were approved starting in 2014 for a variety of cancers including lung cancer, kidney cancer, urothelial cancer, Hodgkin's disease, breast cancer (13), as well as for microsatellite high and mismatch repair deficient solid tumors (14). Other than Sip-T, no other immunotherapeutic modality is approved for use in PCa. However, there are currently many ongoing immunotherapeutic clinical trials to assess their immune and clinical efficacy. In the present review, we will discuss advances made in preclinical trials and the tools used in this research and recent clinical trials.

\section{ONGOING CLINICAL TRIALS}

Several clinical trials have been completed or are ongoing to investigate diverse immunotherapeutic approaches for patients with mCRPC, including vaccines, immune checkpoint inhibitors (ICI) and immunomodulators, adoptive cell transfer $(\mathrm{ACT})$, oncolytic virus-mediated immune response, as well as combinatorial approaches with radiation, chemotherapy, and others. As of May 1, 2019, more than 1100 clinical trials are active (or recruiting) for PCa spanning these different approaches, of which $63 \%$ are therapy based, with $12 \%$ being immunotherapeutic in nature. Figure 1 shows a snapshot of ongoing clinical trials for prostate cancer in mid-2019, with a specific focus on immunotherapies that are being investigated. We provide a detailed description of each type of immunotherapy, as well as provide an overview of ongoing clinical trials for each type of therapy throughout this review.

\section{Vaccine Based Therapies DNA-Based Vaccines}

DNA vaccines elicit an immune response by being transfected, transcribed, and translated by host cells to produce foreign antigens that are recognized by the immune system. DNA vaccines can be designed to exploit tumor associated antigens (TAAs) to mount an immune response that produces a robust proliferation and activation of tumor antigen specific T cells (1518 ), and are an area of current investigation. PCa has a variety of TAAs that can be targeted, including prostate-specific antigen (PSA), prostate-specific membrane antigen (PSMA), prostatic acid phosphatase (PAP), prostate stem cell antigen (PSCA), prostein, $\mathrm{T}$ cell receptor gamma alternate reading frame protein (TARP), Trp-p8, and Six-transmembrane epithelial antigen of the prostate 1 (STEAP1), and NY-ESO-1 $(19,20)$.

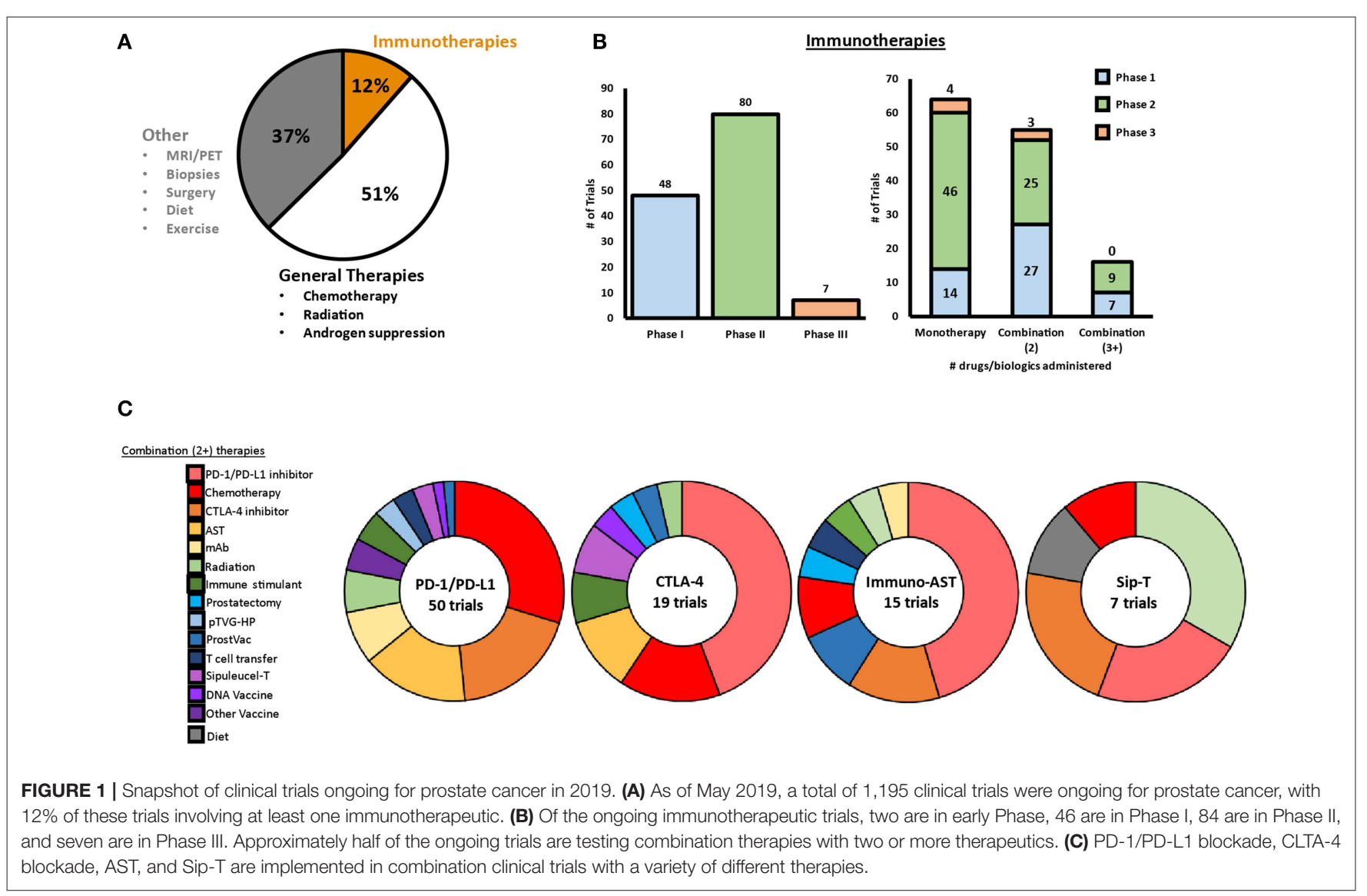


One of the most studied prostate cancer DNA vaccines encodes PAP plus granulocyte-macrophage colony stimulating factor (GM-CSF) (pTVG-HP), which has been tested in a phase I trial of men with biochemically recurrent PCa. Patients in this trial were treated six times every 2 weeks with pTVGHP and GM-CSF. Results from the phase I trial show that the vaccination is safe and that 9 of 22 patients developed $\mathrm{CD} 4^{+}$ and/or $\mathrm{CD}^{+}$PAP specific responses, and patient PSA doubling time increased from 6.5 months pre-treatment to 9.3 months 1 year post treatment (21). In a follow up study by the same group, patient PBMC samples from the original phase I cohort were further assessed for antigen specific $\mathrm{T}$ cell populations and responses. This study found that multiple immunizations were necessary for robust responses as a majority of the PAP specific $\mathrm{T}$ cells were not detectable until after the 6 vaccination regimen was completed (22). pTVG-HP is currently being combined with Sip-T (NCT01706458) and nivolumab (NCT03600350) in phase II clinical trials.

Neoantigen DNA vaccinations are being developed as a personalized therapeutic to stimulate $\mathrm{T}$ cells to specifically attack neoantigen bearing tumor cells. Neoantigen DNA vaccines are developed through the identification of tumor specific antigens through whole exome sequencing of tumor and germline DNA (23). Neoantigen DNA vaccinations are still in early stages of development, however dendritic cell (24) and peptide based $(25,26)$ neoantigen vaccinations have been successful in eliciting $\mathrm{T}$ cell responses in preliminary clinical studies performed in patients with melanoma, primary Glioblastoma, and lung cancer, suggesting that neoantigen DNA vaccinations have the potential to be efficacious in PCa as well. An intensive phase I trial has been initiated that involves a combination treatment regimen with a neoantigen DNA vaccination, nivolumab, ipilimumab, and PROSTVAC in patients with metastatic hormone sensitive prostate cancer (NCT03532217).

\section{Cell-Based Vaccines}

Cell-based vaccination generally consists of autologous or allogenic whole cells, including antigen presenting cells (APCs) and PCa cells that are modified to bear TAAs and/or GMCSF to induce anti-tumor immune responses (27). One cellbased vaccination under investigation is GVAX, which is a whole cell vaccine comprised of castration-sensitive and castrationresistant allogenic prostate cancer cell lines ( $\mathrm{LNCaP}$ and PC3, respectively). The cell lines are engineered to overexpress GMCSF, resulting in the activation of DCs, and then subsequently $\mathrm{T}$ cells, to elicit robust antitumor responses. In an early phase I/II trial, patient survival was extended to 24 months in the low dose cohort (100 million cell booster) and 36.9 months in the high dose cohort ( 300 million cell booster) compared to a predicted 19.5 months (27). Although survival was extended in early trials, two phase III studies (VITAL-1 and VITAL2) failed to show improved outcomes and were closed early due to the lack of clinical efficacy $(28,29)$. A similar phase I trial was performed in which patient tumors were resected and then underwent retroviral transductions to express GMCSF; vaccination activated new $\mathrm{T}$ and $\mathrm{B}$ cell responses against PCa antigen (30). GM-CSF cellular vaccinations are currently not being tested in the clinics for PCa. However, GM-CSF is still being investigated for its use in other types of $\mathrm{PCa}$ vaccines in preclinical testing, such as in combination with norcantharidin (31).

Sip-T is an autologous dendritic cell vaccine generated by ex vivo priming of patient DCs with PA2024 (fusion protein with PAP and GM-CSF) $(32,33)$. Sip-T was the first FDA approved therapeutic cancer vaccine in 2010. Three multicenter phase III clinical trials were performed to assess the efficacy in asymptomatic or minimally symptomatic patients with mCRPC. The first two trials showed no difference in time to tumor progression (TTP), but demonstrated a statistically improved OS benefit among patients treated with Sip-T [25.9 vs. 21.4 months $(P=0.01, \mathrm{HR}, 1.7)$, and 19.0 vs. 15.7 months $(P=0.3, \mathrm{HR}, 1.27)]$ $(34,35)$. A third Phase III clinical trial (IMPACT) enrolled 512 patients who were randomly assigned in a $2: 1$ ratio to Sip-T or placebo. Similarly to the previous two trials, patients receiving Sip-T had a median 4.1 month OS benefit compared to the placebo [ 25.8 vs. 21.7 months $(P=0.02, \mathrm{HR}, 0.77)$ ] while having no significant difference in TTP (14.6 vs. 14.4 weeks) (9). Safety data demonstrated that treatment was overall well-tolerated with no severe adverse events (36). Despite its efficacy and safety, Sip$\mathrm{T}$ is not widely accepted, mainly due to the high cost compared to the degree of benefit (37). Together, these studies ultimately led to the approval of Sip-T for mCRPC. Combination treatments are being investigated in the clinic to enhance the efficacy of Sip-T and include combination with Atezolizumab (Anti-PD-L1) (NCT03024216), Ipilimumab (Anti-CTLA-4) (NCT01804465), radiation (NCT02463799, NCT01818986, NCT01807065), and chemotherapy (NCT01420965).

Chimeric antigen receptor (CAR) $\mathrm{T}$ cells are autologous cells that are engineered ex vivo to express a TCR signaling domain fused with variable regions of an antibody, enabling them to recognize tumor surface antigens in an MHC independent manner (38). CAR T cells targeting CD19 have shown complete responses in B-cell hematologic malignancies (39), suggesting a promising approach with CAR $\mathrm{T}$ cells for treating tumors. A preclinical model utilizing a $4-1 \mathrm{BB}$ containing CAR showed potent anti-tumor activity in an LAPC-9 xenograft model (40). Currently clinical trials involving CAR T cells targeting EpCAM (NCT03013712), PSCA (NCT02744287), PSMA (NCT01140373, NCT03089203), and NY-ESO-1 (NCT03159585) are ongoing.

\section{Peptide-Based Vaccines}

Personalized peptide vaccinations (PPV) utilize immunization with tumor specific peptides that can elicit an immune response to induce cytotoxic T lymphocyte (CTL) activation and subsequent anti-tumor responses. The standard procedure for determining peptide candidates for vaccination is to screen prevaccination patient peptides for their ability to induce a CTL or humoral responses to the peptides in vitro (41). Targets have been identified for HLA-A24 ${ }^{+}$PCa patients, including PAP (42), PSA (43), and PSMA (44).

A randomized phase II study testing the combination treatment of a PPV and estramustine phosphate (EMP) or EMP alone showed improved PFS (8.5 vs. 2.8 months) for the combination treatment, and was deemed tolerable and safe for 
ongoing future clinical trials (45). Another randomized phase II trial reported that the OS of docetaxel-resistant CRPC patients showed improved OS to patients receiving PPV compared to those who did not (17.8 vs. 10.5 months) (46). Based on these findings, a phase III, randomized, placebo-controlled trial testing PPV in docetaxel-refractory mCRPC patients is ongoing (UMIN000011308).

A phase I/IIa dose escalation trial with a peptide vaccine UV1, containing a peptide fragment from telomerase reverse transcriptase (hTERT), was performed with patients who had metastatic hormone-naïve prostate cancer. Overall, a majority of the patients responded to therapy as immune responses were detected in 18 of 21, PSA levels declined in 14 of 21, and 10 of 21 had no evidence of persisting tumors by MRI imaging (47). This phase I/IIa trial is still ongoing (NCT01784913), and there are currently no ongoing phase III trials for testing the efficacy of UV1 for PCa.

\section{Viral Vector-Based Vaccines}

Viral-based vaccines are an immunotherapeutic strategy that utilizes recombinant viral vectors carrying gene sequences of TAAs to mimic natural infection of host immune cells causing specific immune responses against encoded tumor antigens (48). PROSTVAC (TRICOM) is a poxviral-based vaccine regimen consisting of a recombinant attenuated vaccinia and fowlpox virus booster engineered to encode TAAs (PSA) and three costimulatory proteins: B7-1 (CD80), lymphocyte functionassociated antigen 3 (LFA-3) (CD58), and intercellular adhesion molecule-1 (ICAM-1) (CD54) (49). A phase II trial of 125 patients with minimally symptomatic mCRPC randomized patients to receive PROSTVAC or a placebo in a ratio of 2:1. Median OS for patients given PROSTVAC was increased over placebo [25.1 vs. 16.6 months $(P=0.0061, \mathrm{HR}, 0.56)]$, but not for progression free survival (PFS) (50). Another phase II clinical trial was performed with PROSTVAC and GMCSF in 32 men with mCRPC, which showed similar findings with an increased median OS of 26.6 months (predicted 17.4 months by Halabi nomogram) (51). These data led to a randomized, placebo-controlled phase III trial in men with mCRPC. Gulley et al. (52) recently published results from this trial; patients were randomized into three groups that received either PROSTVAC, PROSTVAC + GM-CSF, or placebo. Neither treatment influenced median OS (34.4, 33.2, and 34.2 months, respectively), and patients alive without events (AWE) were similar at 6 months $(29.4,28.0$, and 30.3\%, respectively). Overall, PROSTVAC was safe, but it did not affect OS or AWE in patients with MCRPC (52). These new results suggest that PROSTVAC as a single agent is not effective, and that an immunosuppressive environment could negatively influence the efficacy of the treatment. Combination therapies with PROSTVAC are being investigated for their ability to enhance immune responses. Ongoing combination clinical trials with PROSTVAC include either DNA vaccines (NCT03532217), ICI (NCT02506114, NCT02933255), and chemotherapy (NCT02649855).

Adenovirus 5 (Ad5) is another important vector that is used as an immune agent to immunize against TAAs. A phase I trial was performed to study the immune responses to an Ad5-PSA vaccination in 32 patients with hormone refractory metastatic prostate cancer. In response to vaccination, $34 \%$ of patients generated anti-PSA antibodies, 68\% developed anti-PSA T cell responses, $48 \%$ had an increased PSA doubling time, and 55\% survived longer than predicted (53). An ongoing Phase II clinical trial (NCT00583024) investigating adenovirus/PSA responses in men with hormone refractory prostate cancer showed antiPSA T cell responses were present in $100 \%$ of patients with recurrent disease and $67 \%$ in patients with hormone refractory disease (54). A newly recruiting phase I clinical trial will examine how mCRPC patients will respond to adenoviral PSA (ETBX071), MUC1 (ETBX-061), and ETBX-051 (brachyury) vaccines (NCT03481816). An active Phase I trial is testing ETBX-051, ETBX-061, in addition to an adenoviral CEA vaccine (ETBX011) (NCT03384316).

\section{Immune Checkpoint Inhibitors}

Immune checkpoint inhibitors (ICIs) are antibodies that target regulatory or co-inhibitory signaling molecules, including cytotoxic T-lymphocyte antigen-4 (CTLA-4), programmed cell death-1 (PD-1), and programmed cell death ligand-1 (PD-L1). Blockade of these inhibitory entities results in subsequent $\mathrm{T}$ cell activation and anti-tumor activity (55). To date, PD-1/PD-L1 blockade antibody therapies have been approved for a spectrum of solid tumor malignancies (Table 1). Anti-CTLA-4 antibody therapy is only approved for melanoma and renal cell carcinoma; however, there are multiple ongoing clinical trials with antiCTLA-4 as one of the combination agents. No ICIs are approved specifically for the treatment of $\mathrm{PCa}$, other than for tumors with high microsatellite instability, due to their marginal efficacy in clinical trials. Substantial efforts are being made to assess the efficacy of ICI therapies in combination settings for PCa.

\section{CTLA-4 Blockade}

Ipilimumab, the only FDA approved anti-CTLA-4 monoclonal antibody for treatment of melanoma was and is still being evaluated in several phase I, II, and III clinical trials for patients with $\mathrm{PCa}$ as a single agent or combination therapy. In a phase I/II clinical trial for mCRPC, it was shown that ipilimumab was safe, tolerable, and synergistic with radiotherapy. Of 50 patients given $10 \mathrm{mg} / \mathrm{kg}$ ipilimumab and radiotherapy, eight had PSA declines $(\geq 50 \%)$, one had a complete response, and six had stable disease ranging from 2.8 to 6.1 months (56). A randomized phase III trial was performed to compare ipilimumab with placebo after bone directed radiotherapy in 799 patients who had progressed on docetaxel chemotherapy. In this trial, there was no significant difference in OS between ipilimumab and placebo [11.2 vs. 10 months $(P=0.053, \mathrm{H}, 0.85)]$, but a modest benefit in PFS [4.0 vs. 3.1 months $(P<0.0001, \mathrm{HR}, 0.70)]$ (57). An unplanned subgroup analysis demonstrated that patients with no visceral metastases, low bone alkaline phosphatase levels of $<1.5$ times the upper limit of normal and higher hemoglobin ( $>100 \mathrm{~g} / \mathrm{L}$ ) were more likely to benefit from ipilimumab therapy in terms of overall survival (57). In another phase III trial, ipilimumab was compared with placebo, and there was no significant difference in median OS [28.7 vs. 29.7 months $(P=$ 0.3667 , HR 1.11)], but slight PFS benefit [5.6 vs. 3.8 months 
TABLE 1 | FDA-approved immune checkpoint blocking antibodies.

\begin{tabular}{|c|c|c|c|}
\hline Target & Antibody drug & Trade name & $\begin{array}{l}\text { Tumor Type (FDA Approval } \\
\text { Year) }\end{array}$ \\
\hline \multirow[t]{13}{*}{ PD1 } & \multirow[t]{6}{*}{ Nivolumab (lgG4) } & \multirow[t]{6}{*}{ Opdivo } & Melanoma (2014) \\
\hline & & & $\begin{array}{l}\text { Non-small-cell lung cancer } \\
\text { (2015) }\end{array}$ \\
\hline & & & Hodgkin lymphoma (2016) \\
\hline & & & $\begin{array}{l}\text { Head and neck squamous cell } \\
\text { carcinoma (2016) }\end{array}$ \\
\hline & & & Urothelial carcinoma (2017) \\
\hline & & & Hepatocellular carcinoma (2017) \\
\hline & \multirow{6}{*}{$\begin{array}{l}\text { Pembrolizumumab } \\
\text { (lgG4) }\end{array}$} & \multirow[t]{6}{*}{ Keytruda } & Melanoma (2014) \\
\hline & & & $\begin{array}{l}\text { Non-small-cell lung cancer } \\
\text { (2015) }\end{array}$ \\
\hline & & & $\begin{array}{l}\text { Head and neck squamous cell } \\
\text { carcinoma (2016) }\end{array}$ \\
\hline & & & Hodgkin lymphoma (2017) \\
\hline & & & Urothelial carcinoma (2017) \\
\hline & & & $\begin{array}{l}\text { Gastic and gastroesophageal } \\
\text { carcinoma (2017) }\end{array}$ \\
\hline & Cemiplimab (lgG4) & Libtayo & $\begin{array}{l}\text { Cutaneous squamous cell } \\
\text { carcinoma (2018) }\end{array}$ \\
\hline \multirow[t]{6}{*}{ PD-L1 } & \multirow{2}{*}{$\begin{array}{l}\text { Atezolizumab } \\
\text { (lgG1) }\end{array}$} & \multirow[t]{2}{*}{ Tecentriq } & Urothelial carcinoma (2016) \\
\hline & & & $\begin{array}{l}\text { Non-small-cell lung cancer } \\
(2016)\end{array}$ \\
\hline & \multirow[t]{2}{*}{ Durvalumab (lgG1) } & \multirow[t]{2}{*}{ Imfinzi } & Urothelial carcinoma (2017) \\
\hline & & & $\begin{array}{l}\text { Non-small-cell lung cancer } \\
(2018)\end{array}$ \\
\hline & \multirow[t]{2}{*}{ Avelumab (lgG1) } & \multirow[t]{2}{*}{ Bavencio } & Merkel cell carcinoma (2017) \\
\hline & & & Urothelial carcinoma (2017) \\
\hline CTLA-4 & Ipilimumab (lgG1) & Yervoy & Melanoma (2014) \\
\hline
\end{tabular}

(HR, 0.67) ] and a higher PSA response (23\% vs. $8 \%)(58)$. Due to the ineffectiveness of Ipilimumab alone, it is being tested in a variety of combination trials for patients with $\mathrm{PCa}$, including with radiation (NCT03477864), nivolumab [NCT03333616, NCT03061539, NCT02985957 (Checkmate 650)], chemotherapy (NCT03098160, NCT01688492), and AST (NCT01498978).

\section{PD-1/PD-L1 Blockade}

PD-1 and PD-L1 inhibitors disrupt the interaction of PD1 expressed on the $\mathrm{T}$ cell surface and PD-L1 expressed on tumor or myeloid cells within the tumor microenvironment. Engagement of the PD-1 receptor induces T cell anergy, and thus PD-1/PD-L1 blockade revives $\mathrm{T}$ cell anti-tumor responses. Within the last 5 years, PD-1 and PD-L1 inhibitors have been approved for use in melanoma, non-small-cell cancer, head, and neck squamous cell carcinoma, Hodgkin's lymphoma, urothelial carcinoma, renal cell carcinoma, as well as gastric and gastroesophageal carcinoma [reviewed in (59) and Table 1]. In a phase I trial for $\mathrm{mCRPC}$, the anti-PD1 mAb nivolumab was administered to 17 patients with $\mathrm{mCRPC}$; no objective responses were seen in any patients (60) (NCT00730639). One promising Phase II study recruited 10 patients that previously received enzalutamide and were then treated with pembrolizumab. Three of the patients responded with measurable serum PSA declines, with two of the patients having tumor size reduction in a 12 or 24 -week period (61). In another phase Ib trial, 23 mCRPC patients with PD-L1 positive tumors were treated with the anti-PD1 mAb pembrolizumab; $17.4 \%$ of patients had an objective response rate, with stable disease in $34.8 \%$ of patients, and tumor size reduction in 10 of 21 assessible patients (62). A phase Ia study with atezolizumab, an anti-PDL1 $\mathrm{mAb}$, in patients with mCRPC showed that the drug was well-tolerated with a 56\% 12-month OS (63) (NCT01375842). Together, these results suggest that monotherapy is not sufficient for significant responses in $\mathrm{PCa}$, and thus combinatorial approaches are being investigated. Currently, ongoing PD-1/PDL1 blockade clinical trials include combination with PROSTVAC (NCT02933255), pTVG-HP (NCT03600350), chemotherapy (NCT03572478, NCT03170960, NCT03673787), radium-223 (NCT03093428, NCT02814669), Sip-T (NCT03024216), and CTLA-4 checkpoint inhibitors (NCT03333616).

\section{B7-H3 Blockade}

B7-H3 is a newly investigated immune checkpoint target for immunotherapy. B7-H3 shares $20-27 \%$ amino acid identity with other B7 family members and is found to be expressed by tumor cells and immature dendritic cells (64). The receptor for B7$\mathrm{H} 3$ is unknown. However, overexpression of B7-H3 on cancer cells inhibits $\mathrm{T}$ cell function, and thus contributes to immune evasion $(65,66)$. Recent studies show that prostate tumors that express $\mathrm{B} 7-\mathrm{H} 3$ are positively correlated with a high Gleason score, mCRPC, and tumor stage (67). Monoclonal antibodies targeting $\mathrm{B} 7-\mathrm{H} 3$ are being tested in the clinic as a monotherapy [NCT02628535, NCT02923180 (68), and NCT01391143] in phase I and II trials.

\section{Oncolytic Viruses-Mediated Immune Modulation}

Another field of viral based cancer vaccines are oncolytic viruses (69-72). Oncolytic viruses are designed to specifically target, replicate in, and kill cancerous cells, while keeping normal cells intact. The field of utilizing oncolytic viruses as an immunotherapeutic for prostate cancer is newly emerging and many studies are still in the preclinical stage to study the effects on the immune system. However, one immunotherapeutic oncolytic virus, Ad5-yCD/mutTKSR39rep-hIL12, is currently in clinical trials. A series of Ad5-CD/TK oncolytic viruses have been developed and tested as a therapeutic for prostate cancer. These viruses are designed to deliver two suicide genes- cytosine deaminase (CD) and herpes simplex type 1 thymidine kinase (HSV-1 TK)- to tumor cells. CD functions to convert 5-fluorocytosine into a toxic 5-FU metabolite, while HSV-1 TK phosphorylates ganciclovir, which converts it into a nucleotide analog and inhibits DNA replication (73). Ad5-CD/TK was administered to prostate cancer patients in a Phase I clinical trial and was deemed safe (74), and an improved Ad5-yCD/mutTK $\mathrm{SR}_{39}$-ADP was designed, which contains a more catalytically active mutant herpes TK (SR39) (75). In a phase I trial, nine patients with localized $\mathrm{PCa}$ received Ad5-yCD/mutTK $\mathrm{SR}_{\mathrm{S} 3}-\mathrm{ADP}$ in combination with 
intensity-modulated radiotherapy and no additional toxicities were incurred compared to the first generation Ad5-CD/TKrep. Interestingly, the authors report that patients in the intermediate risk group had improved responses compared to the highrisk group, as $0 \%$ of patients within the intermediate-risk group had adenocarcinoma at their last biopsy (24 months) (75). These findings led to the development of new Ad5 therapy that is modified to express human IL-12 (Ad5yCD/mutTKSR39rep-hIL12), which enhanced T and NK antitumor activity in a preclinical mouse model (76). A Phase I trial recruiting patients with locally recurrent prostate cancer for Ad5-yCD/mutTKSR39rep-hIL12 is underway (NCT02555397).

Another oncolytic virus that has been tested in prostate cancer patients in pelareorep (Reolysin), a reovirus. Reovirus oncolysis is activated by the Ras signaling pathway, and can therefore be harnessed as a therapeutic for cancer $(77,78)$. Reovirus therapy increases the secretion of pro-inflammatory cytokines, increases $\mathrm{CD} 8 \mathrm{~T}$ and $\mathrm{NK}$ cell homing to tumors, and increases expression of MHC class I on tumor cells to present tumor antigens $(79,80)$. In a Phase I trial of 33 patients with malignant solid tumors, five PCa patients were treated with reovirus (type 3 Dearing) for a maximum of 5 days every 4 weeks. Overall, administration of the reovirus was safe with minimal severe adverse event (81). A Phase II clinical trial testing the effects of reovirus in combination with docetaxel and prednisone in patients with MCRPC was also completed, although combination of docetaxel and prednisone with pelareorep presented no survival benefit compared to docetaxel and prednisone alone (82). A Phase II clinical trial with pelareorep in combination with pembrolizumab in patients with pancreatic cancer is ongoing, however there are currently no ongoing trials for peloreorep for prostate cancer.

\section{Combination Immunotherapies}

Despite diverse investigations into immunotherapeutic agents for $\mathrm{PCa}$, the results from each agent as a monotherapy have not shown satisfying benefits. To improve clinical outcomes, combinations of these immune agents with each other or hormonal therapy, chemotherapy, radiation, or surgery may be a necessary and optimal approach. Currently, there are several active clinical trials investigating immunotherapeutic combinations.

\section{Vaccines and Immune Checkpoint Blockades}

Immune checkpoint inhibitors in combination with vaccination can enhance anti-tumor T cell responses. A phase I trial testing ipilimumab in combination with GVAX in 12 chemotherapy naive $\mathrm{MCRPC}$ patients reported that combination therapy led to a PSA decline of $\geq 50$ in $25 \%$ of patients, with minimal adverse events (83). Another phase I trial assessed the combination of ipilimumab and PROSTVAC vaccine in $30 \mathrm{mCRPC}$ patients. In 14 of the 24 chemotherapy naïve patients, PSA declines were observed, with 6 patients having a reduction of $\geq 50 \%$ (49). A study in which 25 mCRPC patients were given combination (either concurrent or sequential) therapy of pembrolizumab and a tumor PAP-specific DNA vaccine showed that 11 of 25 patients had increases in PAP-specific CD8 T cells after treatment. Of the 13 patients that received concurrent combination therapy,
8 patients had serum PSA declines (84). Phase II trials are underway to further investigate these combinations and include Sip-T with anti-PD-1 mAb (CT-011) (NCT01420965), Sip-T with anti-CTLA4 (ipilimumab) (NCT01804465), and PROSTVAC with anti-PD1 (nivolumab) (NCT02933255).

\section{AST and Immunotherapy}

AST is one of the first line therapies after diagnosis with mCRPC. AST has been shown to induce multiple effects on the immune system, such as modulating cancer cell sensitivity to $\mathrm{T}$ cells and increasing $\mathrm{T}$ cell infiltration into the prostate (85). Clinical trials are now investigating combination AST and immunotherapies. A randomized phase II trial evaluating Sip-T with standard AST showed higher cytokine responses and $\mathrm{CD}^{+}$ $\mathrm{T}$ cell activation when Sip-T was administered after AST (86). Several clinical trials testing combinations of immunotherapies and androgen ablation in mCRPC patients are underway, such as enzalutamide with atezolizumab (NCT03016312), pembrolizumab (NCT03753243), or nivolumab and radiation therapy (NCT03543189).

\section{Chemotherapy and Immunotherapy}

Chemotherapeutic drugs function through disrupting normal cell cycle, leading to either cell cycle arrest or apoptosis of tumor cells. Tumor cells that are undergoing apoptosis can be classified as immunogenic cell death (ICD), which enhances the "visibility" of tumor antigens to the immune system. In the process of ICD, tumor cells can release damage associated molecular patterns (DAMPs), such as HMGB1, ATP, and CRT (87), leading to subsequent activation of resident immune cells. The use of ICI in combination with chemotherapy could enhance antitumor immune activity. A variety of chemotherapy combination trials are being performed including: rucaparib and nivolumab (NCT03572478), ipatasertib and atezolizumab (NCT03673787), evofosfamide and ipilimumab (NCT03098160), and cabozantinib with atezolizumab (NCT03170960).

\section{Radiotherapy and Immunotherapy}

Radiotherapy causes tumor cell death and subsequent release of TAAs that can be processed and presented to $\mathrm{CD} 8^{+} \mathrm{T}$ cells $(88,89)$. Although not extensively studied in PCa yet, patients with metastatic pancreatic (90) or melanoma (91) have previously been reported to show tumor regression or complete response after combination immunotherapy and radiotherapy to a limited number of tumor sites inducing an abscopal effect. Radiation therapy, such as Radium-233, brachytherapy, and stereotactic ablative body radiation (SABR), are being combined with Sip-T (NCT02463799, NCT01807065, NCT01818986), pembrolizumab (NCT03093428), and nivolumab (NCT03543189) for treating men with various stages of PCa.

\section{POTENTIAL MECHANISMS OF RESISTANCE OF PROSTATE CANCER TO IMMUNOTHERAPY}

To date, clinical trials of immune therapy for PCa patients have focused on metastatic prostate cancer, with specific 
efforts being made for progressing therapies for patients with castration resistant disease. A dysfunctional immune system in men with $\mathrm{mPC}$ may account for unresponsiveness to current immunotherapy. Patients with metastatic prostate cancer have dysfunctional cellular immunity and an increased immune suppressive tumor microenvironment. These compromised immune functions include, but are not limited to, impaired function and renewal of natural killer (NK) cells $(92,93)$, and impaired expression of $\mathrm{CD} 3 \zeta$ in $\mathrm{NK}$ and $\mathrm{T}$ cells (94), a key signaling molecule for $\mathrm{T}$-cell receptor (TCR) and NK cell activating receptors. Metastatic CRPC patients also have reduced $\mathrm{T}$ cell frequency in the circulation (95), although it is not clear whether it is the outcome of AST or tumormediated modulation of T cell homeostasis. Men with $\mathrm{mPC}$ also have increased suppressive phenotypes of myeloid suppressor cells and regulatory $\mathrm{T}$ cells in the circulation, as well as in the tumor microenvironment (96-98). The compromised cellular immunity and highly immune suppressive tumor microenvironment likely explain the reported low infiltration of effective immune cell types (so-called "cold" tumor) in the primary tumor in men with PCa. Whether lack of immune infiltration is due to inability of effector NK and T cells homing to the tumor, or survival in the local tumor microenvironment, is an open question.

Other potential mechanisms of prostate cancer resistance to immunotherapy have been proposed. One is immune tolerance due to the nature of slow disease progression $(99,100)$. Low mutational tumor burden may contribute to the de novo resistance of prostate cancer to immunotherapy (101), although this view is controversial as stratified genomic analyses revealed higher mutational burden than found in renal cancer (102). Taken together, the immunosuppressive prostate TME creates a challenge for developing effective immunotherapeutics. Development of mechanism-driven immunotherapies that can restore NK and CD8 T cell function, as well as overcome prostate immune suppressive tumor microenvironment, are needed for effective treatment of metastatic prostate cancer.

\section{PROMISING PRECLINICAL STUDIES}

\section{Animal Models}

One widely-used PCa mouse model is TRAMP (transgenic adenocarcinoma of the mouse prostate), which expresses SV40 T antigen under the rat probesin promoter. Due to SV40 dependent disruption of $\mathrm{p} 53$ and $\mathrm{pRb}$ function, TRAMP mice spontaneously develop prostate tumors that are detectable at 18-24 weeks of age (103). The advantage of TRAMP mice tumor progression is that it mimics human pathology well, with natural progression from initial hyperplasia, intraepithelial neoplasia, adenocarcinoma, expression of neuroendocrine markers in older mice, as well as metastasis into lung and lymph node tissues (103). TRAMP tumors develop androgen independence early, providing a good model for androgen-independent disease states (104). Another commonly used mouse model is LADY, which also expresses SV40 under a large promoter fragment of the PB gene (LBP) is also commonly used. The timeline to disease is slightly increased compared to the TRAMP models (10-15 weeks to initial hyperplasia) (105). Other mouse models that are used have prostate specific Cre-lox gene deletion of Pten, p53, or Smad4, and prostate-specific overexpression of c-Myc or N-Myc (106). PDX models (CrownBio) of PCa, specifically CRPC, are being developed for their eventual use in humanized mouse systems. Further research will be needed in the development of humanized PDX models of prostate cancer due to the difficulties of propagating prostate tumors ex vivo (107).

\section{Promising Proof-of-Concept New Therapeutic Investigations}

\section{Targeting Tumor-Released Soluble MIC to Harness NKG2D Pathway}

MIC (major histocompatibility I chain-related molecule) is an NKG2D ligand expressed during early stages of cancer on stressed cells. Engagement of NKG2D with membrane bound MIC results in the stimulation of T and NK cells. However, as the cancer progresses, proteases cleave MIC from the surface, producing soluble MIC (sMIC). sMIC contributes to an increased immunosuppressive tumor microenvironment by promoting myeloid-derived suppressor cells (MDSC) expansion (108) and reducing the expression of NKG2D on T and NK cells (93). High serum concentrations of soluble NKG2D ligands are associated with poor prognosis in a variety of cancers including prostate (93), melanoma (109), and hepatitis B induced hepatocellular carcinoma (HCC) (110). PCa patients with metastatic disease have significantly elevated levels of serum sMIC than those with localized disease. Targeting sMIC with a non-blocking antiMIC antibody can effectively de-bulk prostate tumor burden and eliminate distant metastasis by re-invigorating endogenous innate and adaptive antitumor responses in preclinical models of prostate cancer $(108,111-113)$. Antibody targeting sMIC also sensitizes mouse prostate tumors to treatment with anti-CTLA4 (111) and PD-1/PD-L1 blockade (114).

\section{CLTA-4 and PD-1 Checkpoint Blockade in Combination With MDSC Targeted Therapy}

Myeloid derived suppressor cells (MDSCs) are a recently characterized immune cell subset implicated in inflammatory processes and tumor progression (115). MDSCs promote an immunosuppressive TME through a variety of mechanisms including arginase I production (116), IL-10 immunomodulation (117), expression of PD-L1 (118), and others (119) which all contribute to the inhibition of $\mathrm{T}$ cell function. Recently it was described that IL-23 secreted by MDSCs drives mCRPC development in mice through androgen receptor activation, and that blockade of IL-23 restored sensitivity to androgen deprivation (120). Other therapies have been investigated to inhibit MDSC functionality. Lu et al. (121) tested combination anti-CTLA4 and anti-PD1 (ICI) with either dasatinib (tyrosine kinase inhibitor), cabozantinib (tyrosine kinase inhibitor), or BEZ235 (phosphoinositide 3-kinase/mTOR dual inhibitor) to target tumor MDSCs in a mouse mCRPC model. They found the combination therapy of ICI + dasatinib and ICI + cabozantinib led to lower tumor mass and fewer metastases compared to ICI alone. Additionally, there were lower percentages of intratumoral granulocytic MDSCs, as well as an increase in intratumoral 
$\mathrm{CD}^{+} /$Treg ratios (121). These findings show promise for combination ICI and MDSC suppression therapies.

\section{Oncolytic Virus-Mediated Immunotherapy}

As mentioned earlier, oncolytic viruses are being developed as an immunotherapeutic modality for prostate cancer. Many oncolytic viruses, as a monotherapy, have already completed Phase I/II clinical trials for prostate cancer [reviewed in (69)] with no survival benefit for patients. Preclinical studies are shedding light on how oncolytic viruses impact the immune system to generate anti-tumor responses. Oncolytic viruses have been genetically modified to express human cytokines and other immune modulators, such as bispecific T cell engagers (BiTEs).

In one preclinical model, mice bearing CMR22 prostate tumors were treated with oncolytic herpes simplex virus-1 (oHSV) expressing human IL-12 (NV1042) in combination with vinblastine, a microtube disrupting agent. Combination of NV1042 and vinblastine resulted in reduced tumor growth compared to either treatment alone $(122,123)$. Also in development in preclinical studies is an oncolytic adenovirus expressing BiTEs. In this study, fresh prostate biopsies were treated with an oncolytic group B adenovirus, enadenotucirev (EnAd), to express a BiTE specific for fibroblast activation protein (found on cancer associated fiborblasts) and CD3E. Treatment with the EnAd-BiTE led to an increase in T cell activation and cytotoxicity against tumor stromal fibroblasts (124). These are exciting new developments in harnessing the unique feature of oncolytic virus to prime tumor microenvironment for active immune responses.

\section{CONCLUDING REMARKS}

In all, there is substantial progress being made in understanding the biology of cancer immunotherapy for prostate cancer. Within the last 10 years there have been a series of results from mono-immunotherapy trials which have resulted in minimal survival enhancement in mCRPC patients, leading to a need to investigate combinatorial therapeutic approaches. The immunosuppressive environment within PCa poses a challenge

\section{REFERENCES}

1. Siegel RL, Miller KD, Jemal A. Cancer statistics, 2018. CA Cancer J Clin. (2018) 68:7-30. doi: 10.3322/caac.21442

2. Heidenreich A, Bastian PJ, Bellmunt J, Bolla M, Joniau S, van der Kwast T, et al. EAU guidelines on prostate cancer. Part II: treatment of advanced, relapsing, and castration-resistant prostate cancer. Eur Urol. (2014) 65:46779. doi: 10.1016/j.eururo.2013.11.002

3. Shelley M, Harrison C, Coles B, Staffurth J, Wilt TJ, Mason MD. Chemotherapy for hormone-refractory prostate cancer. Cochrane database Syst Rev. (2006) 8:CD005247. doi: 10.1002/14651858.CD005247.pub2

4. Petrylak DP, Tangen CM, Hussain MHA, Lara PNJ, Jones JA, Taplin ME, et al. Docetaxel and estramustine compared with mitoxantrone and prednisone for advanced refractory prostate cancer. N Engl J Med. (2004) 351:1513-20. doi: 10.1056/NEJMoa041318

5. de Bono JS, Logothetis CJ, Molina A, Fizazi K, North S, Chu L, et al. Abiraterone and increased survival in metastatic prostate cancer. $N$ Engl J Med. (2011) 364:1995-2005. doi: 10.1056/NEJMoa1014618 the development of effective immunotherapies. One general trend in current combinatorial approaches involves checkpoint blockade inhibitors with vaccination (cell, viral, DNA, or peptide based); "hitting the brakes" on immunosuppression, and "pushing the gas pedal" for immune activation.

Other immunosuppressive mechanisms within PCa are being identified through preclinical trials, leading to new therapeutic targets that could be tested in the clinic within the next few years. As new technologies become available, in depth immune cell characterization within MCRPC tumors will be necessary to gain a better understanding of other, currently unidentified, immunosuppressive cell types that may be present. Such cellular characterizations could pave the way for the discovery of new therapeutic drug targets.

Overall, discovery of single agent immunotherapies for prostate and other "cold" cancers has been robust in current years. As results are coming out of these studies, it is clear that combinatorial approaches will be needed to enhance immune responses in prostate cancer patients. There are currently over one hundred immunotherapy based clinical trials that are ongoing for prostate cancer, many of which are testing combination therapies. As we begin to see the results of these ongoing studies, as well as new therapeutics moving into the clinic, we will understand novel ways to increase the potential of immunotherapies for prostate cancer.

\section{AUTHOR CONTRIBUTIONS}

$\mathrm{AB}$ and JW wrote manuscript. $\mathrm{AU}, \mathrm{AM}, \mathrm{DV}$, JS, and JW edited and revised manuscript.

\section{FUNDING}

NIH-NCI grant 1R01CA208246, 1R01CA204021, and R01CA212409 (to JW); by the Department of Defense-Prostate Cancer Research Program award W81XWH-15-1-0406 and W81XWH-17-1-0642 (to JW); and NIC/NCI Prostate Cancer SPORE P50 CA180995.
6. Scher HI, Fizazi K, Saad F, Taplin M-E, Sternberg CN, Miller K, et al. Increased survival with enzalutamide in prostate cancer after chemotherapy. N Engl J Med. (2012) 367:1187-97. doi: 10.1056/NEJMoa1207506

7. Parker C, Nilsson S, Heinrich D, Helle SI, O'Sullivan JM, Fossa SD, et al. Alpha emitter radium-223 and survival in metastatic prostate cancer. $N$ Engl J Med. (2013) 369:213-23. doi: 10.1056/NEJMoa1213755

8. Patel SA, Hoffman-Censits J. Cabazitaxel in the treatment of metastatic castration-resistant prostate cancer: patient selection and special considerations. Onco Targets Ther. (2017) 10:4089-98. doi: 10.2147/OTT.S103532

9. Kantoff PW, Higano CS, Shore ND, Berger ER, Small EJ, Penson DF, et al. Sipuleucel-T immunotherapy for castration-resistant prostate cancer. $\mathrm{N} \mathrm{Engl}$ J Med. (2010) 363:411-22. doi: 10.1056/NEJMoa1001294

10. Moreira DM, Howard LE, Sourbeer KN, Amarasekara HS, Chow LC, Cockrell DC, et al. Predicting time from metastasis to overall survival in castration-resistant prostate cancer: results from SEARCH. Clin Genitourin Cancer. (2017) 15:60-6.e2. doi: 10.1016/j.clgc.201 6.08 .018 
11. Beer TM, Armstrong AJ, Rathkopf DE, Loriot Y, Sternberg CN, Higano CS, et al. Enzalutamide in metastatic prostate cancer before chemotherapy. $N$ Engl J Med. (2014) 371:424-33. doi: 10.1056/NEJMoa1405095

12. Hodi FS, O’Day SJ, McDermott DF, Weber RW, Sosman JA, Haanen JB, et al. Improved survival with ipilimumab in patients with metastatic melanoma. $N$ Engl J Med. (2010) 363:711-23. doi: 10.1056/NEJMoa1003466

13. Tang J, Yu JX, Hubbard-Lucey VM, Neftelinov ST, Hodge JP, Lin Y. The clinical trial landscape for PD1/PDL1 immune checkpoint inhibitors. Nat Rev Drug Discov. (2018) 17:854. doi: 10.1038/nrd.2018.210

14. Zhao P, Li L, Jiang X, Li Q. Mismatch repair deficiency/microsatellite instability-high as a predictor for anti-PD-1/PD-L1 immunotherapy efficacy. J Hematol Oncol. (2019) 12:54. doi: 10.1186/s13045-019-0738-1

15. Cole G, McCaffrey J, Ali AA, McCarthy HO. DNA vaccination for prostate cancer: key concepts and considerations. Cancer Nanotechnol. (2015) 6:2. doi: 10.1186/s12645-015-0010-5

16. Yang B, Jeang J, Yang A, Wu TC, Hung C-F. DNA vaccine for cancer immunotherapy. Hum Vaccin Immunother. (2014) 10:3153-64. doi: $10.4161 / 21645515.2014 .980686$

17. Zahm CD, Colluru VT, McNeel DG. DNA vaccines for prostate cancer. Pharmacol Ther. (2017) 174:27-42. doi: 10.1016/j.pharmthera.2017.02.016

18. Alam S, McNeel DG. DNA vaccines for the treatment of prostate cancer. Exp Rev Vaccines. (2010) 9:731-45. doi: 10.1586/erv.10.64

19. Kiessling A, Wehner R, Fussel S, Bachmann M, Wirth MP, Schmitz M. Tumor-associated antigens for specific immunotherapy of prostate cancer. Cancers. (2012) 4:193-217. doi: 10.3390/cancers4010193

20. Gati A, Lajmi N, Derouiche A, Marrakchi R, Chebil M, Benammar-Elgaaied A. NY-ESO-1 expression and immunogenicity in prostate cancer patients. Tunis Med. (2011) 89:779-83.

21. McNeel DG, Dunphy EJ, Davies JG, Frye TP, Johnson LE, Staab MJ, et al. Safety and immunological efficacy of a DNA vaccine encoding prostatic acid phosphatase in patients with stage D0 prostate cancer. J Clin Oncol. (2009) 27:4047-54. doi: 10.1200/JCO.2008.19.9968

22. Becker JT, Olson BM, Johnson LE, Davies JG, Dunphy EJ, McNeel DG. DNA vaccine encoding prostatic acid phosphatase. (PAP) elicits long-term T-cell responses in patients with recurrent prostate cancer. J Immunother. (2010) 33:639-47. doi: 10.1097/CJI.0b013e3181dda23e

23. Guo Y, Lei K, Tang L. Neoantigen Vaccine delivery for personalized anticancer immunotherapy. Front Immunol. (2018) 9:1499. doi: 10.3389/fimmu.2018.01499

24. Carreno BM, Magrini V, Becker-Hapak M, Kaabinejadian S, Hundal J, Petti AA, et al. Cancer immunotherapy. A dendritic cell vaccine increases the breadth and diversity of melanoma neoantigen-specific T cells. Science. (2015) 348:803-8. doi: 10.1126/science.aaa3828

25. Sahin U, Derhovanessian E, Miller M, Kloke B-P, Simon P, Lower M, et al. Personalized RNA mutanome vaccines mobilize poly-specific therapeutic immunity against cancer. Nature. (2017) 547:222-6.

26. Ott PA, Hu Z, Keskin DB, Shukla SA, Sun J, Bozym DJ, et al. An immunogenic personal neoantigen vaccine for patients with melanoma. Nature. (2017) 547:217-21. doi: 10.1038/nature22991

27. Small EJ, Sacks N, Nemunaitis J, Urba WJ, Dula E, Centeno AS, et al. Granulocyte macrophage colony-stimulating factor-secreting allogeneic cellular immunotherapy for hormone-refractory prostate cancer. Clin Cancer Res. (2007) 13:3883-91. doi: 10.1158/1078-0432.CCR-06-2937

28. Demkow EST, Gerritsen W. A phase III trial of GVAX immunotherapy for prostate cancer in combination with docetaxel versus docetaxel plus prednisone in symptomatic, castration-resistant prostate cancer (CRPC). In Proc 2009 Genitourin Cancer Symp. Orlando, FL (2009).

29. Higano CS, Corman JM, Smith DC, Centeno AS, Steidle CP, Gittleman M, et al. Phase $1 / 2$ dose-escalation study of a GM-CSF-secreting, allogeneic, cellular immunotherapy for metastatic hormone-refractory prostate cancer. Cancer. (2008) 113:975-84. doi: 10.1002/cncr.23669

30. Simons JW, Mikhak B, Chang JF, DeMarzo AM, Carducci MA, Lim M, et al. Induction of immunity to prostate cancer antigens: results of a clinical trial of vaccination with irradiated autologous prostate tumor cells engineered to secrete granulocyte-macrophage colony-stimulating factor using ex vivo gene transfer. Cancer Res. (1999) 59:5160-8.

31. Mo L, Zhang X, Shi X, Wei L, Zheng D, Li H, et al. Norcantharidin enhances antitumor immunity of GM-CSF prostate cancer cells vaccine by inducing apoptosis of regulatory T cells. Cancer Sci. (2018) 109:2109-18. doi: $10.1111 /$ cas. 13639

32. Burch PA, Breen JK, Buckner JC, Gastineau DA, Kaur JA, Laus RL, et al. Priming tissue-specific cellular immunity in a phase I trial of autologous dendritic cells for prostate cancer. Clin Cancer Res. (2000) 6:2175-82.

33. Anassi E, Ndefo UA. Sipuleucel-T. (provenge) injection: the first immunotherapy agent. (vaccine) for hormone-refractory prostate cancer. $P$ T. (2011) 36:197-202.

34. Small EJ, Schellhammer PF, Higano CS, Redfern CH, Nemunaitis JJ, Valone FH, et al. Placebo-controlled phase III trial of immunologic therapy with sipuleucel-T. (APC8015) in patients with metastatic, asymptomatic hormone refractory prostate cancer. J Clin Oncol. (2006) 24:3089-94. doi: 10.1200/JCO.2005.04.5252

35. Higano CS, Schellhammer PF, Small EJ, Burch PA, Nemunaitis J, Yuh L, et al. Integrated data from 2 randomized, double-blind, placebo-controlled, phase 3 trials of active cellular immunotherapy with sipuleucel-T in advanced prostate cancer. Cancer. (2009) 115:3670-9. doi: 10.1002/cncr.24429

36. Hall SJ, Klotz L, Pantuck AJ, George DJ, Whitmore JB, Frohlich MW, et al. Integrated safety data from 4 randomized, double-blind, controlled trials of autologous cellular immunotherapy with sipuleucel-T in patients with prostate cancer. J Urol. (2011) 186:877-81. doi: 10.1016/j.juro.2011.04.070

37. Holko P, Kawalec P. Economic evaluation of sipuleucel-T immunotherapy in castration-resistant prostate cancer. Expert Rev Anticancer Ther. (2014) 14:63-73. doi: 10.1586/14737140.2014.856270

38. Sadelain M, Brentjens R, Riviere I. The basic principles of chimeric antigen receptor design. Cancer Discov. (2013) 3:388-98. doi: 10.1158/2159-8290.CD-12-0548

39. Maude SL, Teachey DT, Porter DL, Grupp SA. CD19-targeted chimeric antigen receptor T-cell therapy for acute lymphoblastic leukemia. Blood. (2015) 125:4017-23. doi: 10.1182/blood-2014-12-580068

40. Priceman SJ, Gerdts EA, Tilakawardane D, Kennewick KT, Murad JP, Park $\mathrm{AK}$, et al. Co-stimulatory signaling determines tumor antigen sensitivity and persistence of CAR T cells targeting PSCA+ metastatic prostate cancer. Oncoimmunology. (2018) 7:e1380764. doi: 10.1080/2162402X.2017.1380764

41. Noguchi M, Sasada T, Itoh K. Personalized peptide vaccination: a new approach for advanced cancer as therapeutic cancer vaccine. Cancer Immunol Immunother. (2013) 62:919-29. doi: 10.1007/s00262-012-1379-1

42. Inoue Y, Takaue Y, Takei M, Kato K, Kanai S, Harada Y, et al. Induction of tumor specific cytotoxic $t$ lymphocytes in prostate cancer using prostatic acid phosphatase derived hla-a2402 binding peptide. J Urol. (2001) 166:1508-13. doi: 10.1016/S0022-5347(05)65821-1

43. Harada M, Kobayashi K, Matsueda S, Nakagawa M, Noguchi M, Itoh K. Prostate-specific antigen-derived epitopes capable of inducing cellular and humoral responses in HLA-A24+ prostate cancer patients. Prostate. (2003) 57:152-9. doi: 10.1002/pros.10280

44. Kobayashi K, Noguchi M, Itoh K, Harada M. Identification of a prostatespecific membrane antigen-derived peptide capable of eliciting both cellular and humoral immune responses in HLA-A24+ prostate cancer patients. Cancer Sci. (2003) 94:622-7. doi: 10.1111/j.1349-7006.2003.tb01493.x

45. Noguchi M, Kakuma T, Uemura H, Nasu Y, Kumon H, Hirao Y, et al. A randomized phase II trial of personalized peptide vaccine plus low dose estramustine phosphate. (EMP) versus standard dose EMP in patients with castration resistant prostate cancer. Cancer Immunol Immunother. (2010) 59:1001-9. doi: 10.1007/s00262-010-0822-4

46. Noguchi M, Moriya F, Suekane S, Matsuoka K, Arai G, Matsueda S, et al. Phase II study of personalized peptide vaccination for castration-resistant prostate cancer patients who failed in docetaxel-based chemotherapy. Prostate. (2012) 72:834-45. doi: 10.1002/pros.21485

47. Lilleby W, Gaudernack G, Brunsvig PF, Vlatkovic L, Schulz M, Mills K, et al. Phase I/IIa clinical trial of a novel hTERT peptide vaccine in men with metastatic hormone-naive prostate cancer. Cancer Immunol Immunother. (2017) 66:891-901. doi: 10.1007/s00262-017-1994-y

48. Sultan H, Fesenkova VI, Addis D, Fan AE, Kumai T, Wu J, et al. Designing therapeutic cancer vaccines by mimicking viral infections. Cancer Immunol Immunother. (2017) 66:203-13. doi: 10.1007/s00262-016-1834-5

49. Madan RA, Bilusic M, Heery C, Schlom J, Gulley JL. Clinical evaluation of TRICOM vector therapeutic cancer vaccines. Semin Oncol. (2012) 39:296304. doi: 10.1053/j.seminoncol.2012.02.010 
50. Kantoff PW, Schuetz TJ, Blumenstein BA, Glode LM, Bilhartz DL, Wyand $\mathrm{M}$, et al. Overall survival analysis of a phase II randomized controlled trial of a Poxviral-based PSA-targeted immunotherapy in metastatic castration-resistant prostate cancer. J Clin Oncol. (2010) 28:1099-105. doi: $10.1200 /$ JCO.2009.25.0597

51. Gulley JL, Arlen PM, Madan RA, Tsang K-Y, Pazdur MP, Skarupa $\mathrm{L}$, et al. Immunologic and prognostic factors associated with overall survival employing a poxviral-based PSA vaccine in metastatic castrateresistant prostate cancer. Cancer Immunol Immunother. (2010) 59:663-74. doi: $10.1007 / \mathrm{s} 00262-009-0782-8$

52. Gulley JL, Borre M, Vogelzang NJ, Ng S, Agarwal N, Parker CC, et al. Phase III Trial of PROSTVAC in asymptomatic or minimally symptomatic metastatic castration-resistant prostate cancer. J Clin Oncol. (2019) 37:105161. doi: $10.1200 / \mathrm{JCO} .18 .02031$

53. Lubaroff DM, Konety BR, Link B, Gerstbrein J, Madsen T, Shannon M, et al. Phase I clinical trial of an adenovirus/prostate-specific antigen vaccine for prostate cancer: safety and immunologic results. Clin Cancer Res. (2009) 15:7375-80. doi: 10.1158/1078-0432.CCR-09-1910

54. Lubaroff DM, Williams RD, Vaena D, Joudi F, Brown J, Smith M, et al. An ongoing phase II trial of an adenovirus/PSA vaccine for prostate cancer. In: 103rd Annu Meet Am Assoc Cancer Res. Chicago, IL (2012).

55. Wei SC, Duffy CR, Allison JP. Fundamental mechanisms of immune checkpoint blockade therapy. Cancer Discov. (2018) 8:1069-86. doi: 10.1158/2159-8290.CD-18-0367

56. Slovin SF, Higano CS, Hamid O, Tejwani S, Harzstark A, Alumkal JJ, et al. Ipilimumab alone or in combination with radiotherapy in metastatic castration-resistant prostate cancer: results from an open-label, multicenter phase I/II study. Ann Oncol Off J Eur Soc Med Oncol. (2013) 24:1813-21. doi: $10.1093 /$ annonc/mdt107

57. Kwon ED, Drake CG, Scher HI, Fizazi K, Bossi A, van den Eertwegh AJM, et al. Ipilimumab versus placebo after radiotherapy in patients with metastatic castration-resistant prostate cancer that had progressed after docetaxel chemotherapy. (CA184-043): a multicentre, randomised, double-blind, phase 3 trial. Lancet Oncol. (2014) 15:700-712. doi: 10.1016/S1470-2045(14)70189-5

58. Beer TM, Kwon ED, Drake CG, Fizazi K, Logothetis C, Gravis G, et al. Randomized, double-blind, phase III Trial of ipilimumab versus placebo in asymptomatic or minimally symptomatic patients with metastatic chemotherapy-naive castration-resistant prostate cancer. J Clin Oncol. (2017) 35:40-7. doi: 10.1200/JCO.2016.69.1584

59. Gong J, Chehrazi-Raffle A, Reddi S, Salgia R. Development of PD-1 and PDL1 inhibitors as a form of cancer immunotherapy: a comprehensive review of registration trials and future considerations. J Immunother cancer. (2018) 6:8. doi: 10.1186/s40425-018-0316-z

60. Topalian SL, Hodi FS, Brahmer JR, Gettinger SN, Smith DC, McDermott DF, et al. Safety, activity, and immune correlates of anti-PD-1 antibody in cancer. N Engl J Med. (2012) 366:2443-54. doi: 10.1056/NEJMoa1200690

61. Graff JN, Alumkal JJ, Drake CG, Thomas GV, Redmond WL, Farhad M, et al. Early evidence of anti-PD-1 activity in enzalutamide-resistant prostate cancer. Oncotarget. (2016) 7:52810-7. doi: 10.18632/oncotarget.10547

62. Hansen AR, Massard C, Ott PA, Haas NB, Lopez JS, Ejadi S, et al. Pembrolizumab for advanced prostate adenocarcinoma: findings of the KEYNOTE-028 study. Ann Oncol Off J Eur Soc Med Oncol. (2018) 29:180713. doi: $10.1093 /$ annonc/mdy232

63. Kim JW, Shaffer DR, Massard C, Powles T, Harshman LC, Braiteh FS, et al. A phase Ia study of safety and clinical activity of atezolizumab. (atezo) in patients. (pts) with metastatic castrationresistant prostate cancer. (mCRPC). J Clin Oncol. (2018) 36:187. doi: 10.1200/JCO.2018.36.6_suppl.187

64. Chapoval AI, Ni J, Lau JS, Wilcox RA, Flies DB, Liu D, et al. B7-H3: A costimulatory molecule for $\mathrm{T}$ cell activation and IFN $-\gamma$ production. Nat Immunol. (2001) 2:269-74. doi: 10.1038/85339

65. Castellanos JR, Purvis IJ, Labak CM, Guda MR, Tsung AJ, Velpula KK, et al. B7-H3 role in the immune landscape of cancer. Am J Clin Exp Immunol. (2017) 6:66-75.

66. Picarda E, Ohaegbulam KC, Zang X. Molecular pathways: targeting B7H3. (CD276) for human cancer immunotherapy. Clin Cancer Res. (2016) 22:3425-31. doi: 10.1158/1078-0432.CCR-15-2428
67. Benzon B, Zhao SG, Haffner MC, Takhar M, Erho N, Yousefi K, et al. Correlation of B7-H3 with androgen receptor, immune pathways and poor outcome in prostate cancer: an expression-based analysis. Prostate Cancer Prostatic Dis. (2017) 20:28-35. doi: 10.1038/pcan.2016.49

68. Shenderov E, Demarzo A, Boudadi K, Allaf M, Wang H, Chapman C, et al. Phase II neoadjuvant and immunologic study of B7-H3 targeting with enoblituzumab in localized intermediate- and high-risk prostate cancer. $J$ Clin Oncol. (2018) 36:TPS5099. doi: 10.1200/JCO.2018.36.15_suppl.TPS5099

69. Lee P, Gujar S. Potentiating prostate cancer immunotherapy with oncolytic viruses. Nat Rev Urol. (2018) 15:235-50. doi: 10.1038/nrurol.2018.10

70. Bartlett DL, Liu Z, Sathaiah M, Ravindranathan R, Guo Z, He Y, et al. Oncolytic viruses as therapeutic cancer vaccines. Mol Cancer. (2013) 12:103. doi: 10.1186/1476-4598-12-103

71. Russell SJ, Barber GN. Oncolytic viruses as antigen-agnostic cancer vaccines. Cancer Cell. (2018) 33:599-605. doi: 10.1016/j.ccell.2018.03.011

72. Taguchi S, Fukuhara H, Homma Y, Todo T. Current status of clinical trials assessing oncolytic virus therapy for urological cancers. Int J Urol. (2017) 24:342-51. doi: $10.1111 /$ iju. 13325

73. Rogulski KR, Wing MS, Paielli DL, Gilbert JD, Kim JH, Freytag SO. Double suicide gene therapy augments the antitumor activity of a replication-competent lytic adenovirus through enhanced cytotoxicity and radiosensitization. Hum Gene Ther. (2000) 11:67-76. doi: 10.1089/10430340050016166

74. Freytag SO, Khil M, Stricker H, Peabody J, Menon M, DePeralta-Venturina $\mathrm{M}$, et al. Phase I study of replication-competent adenovirus-mediated double suicide gene therapy for the treatment of locally recurrent prostate cancer. Cancer Res. (2002) 62:4968-76.

75. Freytag SO, Movsas B, Aref I, Stricker H, Peabody J, Pegg J, et al. Phase I trial of replication-competent adenovirus-mediated suicide gene therapy combined with IMRT for prostate cancer. Mol Ther. (2007) 15:1016-23. doi: $10.1038 / \mathrm{mt}$. sj. 6300120

76. Freytag SO, Barton KN, Zhang Y. Efficacy of oncolytic adenovirus expressing suicide genes and interleukin-12 in preclinical model of prostate cancer. Gene Ther. (2013) 20:1131-9. doi: 10.1038/gt.2013.40

77. Coffey MC, Strong JE, Forsyth PA, Lee PW. Reovirus therapy of tumors with activated Ras pathway. Science. (1998) 282:1332-4. doi: $10.1126 /$ science. 282.5392 .1332

78. Phillips MB, Stuart JD, Rodríguez Stewart RM, Berry JT, Mainou BA, Boehme $\mathrm{KW}$. Current understanding of reovirus oncolysis mechanisms. Oncolyt Virother. (2018) 7:53-63. doi: 10.2147/OV.S143808

79. Gujar SA, Pan DA, Marcato P, Garant KA, Lee PWK. Oncolytic virusinitiated protective immunity against prostate cancer. Mol Ther. (2011) 19:797-804. doi: 10.1038/mt.2010.297

80. Thirukkumaran CM, Nodwell MJ, Hirasawa K, Shi Z-Q, Diaz R, Luider $\mathrm{J}$, et al. Oncolytic viral therapy for prostate cancer: efficacy of reovirus as a biological therapeutic. Cancer Res. (2010) 70:2435-44. doi: 10.1158/0008-5472.CAN-09-2408

81. Vidal L, Pandha HS, Yap TA, White CL, Twigger K, Vile RG, et al. A phase I study of intravenous oncolytic reovirus type 3 Dearing in patients with advanced cancer. Clin Cancer Res. (2008) 14:7127-37. doi: 10.1158/1078-0432.CCR-08-0524

82. Williams ES, Rodriguez-Bravo V, Chippada-Venkata U, De Ia Iglesia-Vicente J, Gong Y, Galsky M, et al. Generation of prostate cancer patient derived xenograft models from circulating tumor cells. J Vis Exp. (2015) 20:53182. doi: $10.3791 / 53182$

83. van den Eertwegh AJM, Versluis J, van den Berg HP, Santegoets SJAM, van Moorselaar RJA, van der Sluis TM, et al. Combined immunotherapy with granulocyte-macrophage colony-stimulating factor-transduced allogeneic prostate cancer cells and ipilimumab in patients with metastatic castrationresistant prostate cancer: a phase 1 dose-escalation trial. Lancet Oncol. (2012) 13:509-17. doi: 10.1016/S1470-2045(12)70007-4

84. McNeel DG, Eickhoff JC, Wargowski E, Zahm C, Staab MJ, Straus J, et al. Concurrent, but not sequential, PD-1 blockade with a DNA vaccine elicits anti-tumor responses in patients with metastatic, castration-resistant prostate cancer. Oncotarget. (2018) 9:25586-96. doi: $10.18632 /$ oncotarget. 25387

85. Mercader M, Bodner BK, Moser MT, Kwon PS, Park ES, Manecke RG, et al. $\mathrm{T}$ cell infiltration of the prostate induced by androgen withdrawal in 
patients with prostate cancer. Proc Natl Acad Sci USA. (2001) 98:14565-70. doi: 10.1073/pnas. 251140998

86. Antonarakis ES, Kibel AS, Yu EY, Karsh LI, Elfiky A, Shore ND, et al. Sequencing of sipuleucel-T and androgen deprivation therapy in men with hormone-sensitive biochemically recurrent prostate cancer: a phase II randomized trial. Clin Cancer Res. (2017) 23:2451-9. doi: 10.1158/1078-0432.CCR-16-1780

87. Wang Y-J, Fletcher R, Yu J, Zhang L. Immunogenic effects of chemotherapy-induced tumor cell death. Genes Dis. (2018) 5:194-203. doi: 10.1016/j.gendis.2018.05.003

88. Formenti SC, Demaria S. Combining radiotherapy and cancer immunotherapy: a paradigm shift. J Natl Cancer Inst. (2013) 105:256-65. doi: 10.1093/jnci/djs629

89. Lee Y, Auh SL, Wang Y, Burnette B, Wang Y, Meng Y, et al. Therapeutic effects of ablative radiation on local tumor require CD8 $+\mathrm{T}$ cells: changing strategies for cancer treatment. Blood. (2009) 114:589-95. doi: 10.1182/blood-2009-02-206870

90. Balar A V, Galsky MD, Rosenberg JE, Powles T, Petrylak DP, Bellmunt $\mathrm{J}$, et al. Atezolizumab as first-line treatment in cisplatin-ineligible patients with locally advanced and metastatic urothelial carcinoma: a single-arm, multicentre, phase 2 trial. Lancet. (2017) 389:67-76. doi: 10.1016/S0140-6736(16)32455-2

91. Haymaker CL, Kim D, Uemura M, Vence LM, Phillip A, McQuail N, et al. Metastatic melanoma patient had a complete response with clonal expansion after whole brain radiation and PD-1 blockade. Cancer Immunol Res. (2017) 5:100-5. doi: 10.1158/2326-6066.CIR-16-0223

92. Liu G, Lu S, Wang X, Page ST, Higano CS, Plymate SR, et al. Perturbation of NK cell peripheral homeostasis accelerates prostate carcinoma metastasis. $J$ Clin Invest. (2013) 123:4410-22. doi: 10.1172/JCI69369

93. Wu JD, Higgins LM, Steinle A, Cosman D, Haugk K, Plymate SR. Prevalent expression of the immunostimulatory MHC class I chain-related molecule is counteracted by shedding in prostate cancer. J Clin Invest. (2004) 114:560-8. doi: 10.1172/JCI22206

94. Healy CG, Simons JW, Carducci MA, DeWeese TL, Bartkowski M, Tong $\mathrm{KP}$, et al. Impaired expression and function of signal-transducing zeta chains in peripheral $\mathrm{T}$ cells and natural killer cells in patients with prostate cancer. Cytometry. (1998) 32:109-19. doi: 10.1002/(SICI)10970320(19980601)32:2<109::AID-CYTO6>3.0.CO;2-G

95. Pal SK, Moreira D, Won H, White SW, Duttagupta P, Lucia M, et al. Reduced T-cell numbers and elevated levels of immunomodulatory cytokines in metastatic prostate cancer patients de novo resistant to abiraterone and/or enzalutamide therapy. Int J Mol Sci. (2019) 20:1831. doi: 10.3390/ijms20081831

96. Lopez-Bujanda Z, Drake CG. Myeloid-derived cells in prostate cancer progression: phenotype and prospective therapies. J Leukoc Biol. (2017) 102:393-406. doi: 10.1189/jlb.5VMR1116-491RR

97. Idorn M, Kollgaard T, Kongsted P, Sengelov L, Thor Straten P. Correlation between frequencies of blood monocytic myeloid-derived suppressor cells, regulatory $\mathrm{T}$ cells and negative prognostic markers in patients with castration-resistant metastatic prostate cancer. Cancer Immunol Immunother. (2014) 63:1177-87. doi: 10.1007/s00262-014-1591-2

98. Chi N, Tan Z, Ma K, Bao L, Yun Z. Increased circulating myeloid-derived suppressor cells correlate with cancer stages, interleukin-8 and-6 in prostate cancer. Int J Clin Exp Med. (2014) 7:3181-92.

99. Zlotta AR, Egawa S, Pushkar D, Govorov A, Kimura T, Kido M, et al. Prevalence of prostate cancer on autopsy: cross-sectional study on unscreened Caucasian and Asian men. J Natl Cancer Inst. (2013) 105:1050-8. doi: $10.1093 /$ jnci/djt151

100. Whittemore AS, Cirillo PM, Feldman D, Cohn BA. Prostate specific antigen levels in young adulthood predict prostate cancer risk: results from a cohort of Black and White Americans. J Urol. (2005) 174:872-6; discussion 876. doi: 10.1097/01.ju.0000169262.18000.8a

101. Maleki Vareki S. High and low mutational burden tumors versus immunologically hot and cold tumors and response to immune checkpoint inhibitors. J Immunother Cancer. (2018) 6:157. doi: 10.1186/s40425-018-0479-7

102. Chen YP, Zhang Y, Lv JW, Li YQ, Wang YQ, He QM, et al. Genomic analysis of tumor microenvironment immune types across 14 solid cancer types: immunotherapeutic implications. Theranostics. (2017) 7:3585-94. doi: $10.7150 /$ thno. 21471

103. Gelman IH. How the TRAMP model revolutionized the study of prostate cancer progression. Cancer Res. (2016) 76:6137-9. doi: 10.1158/0008-5472.CAN-16-2636

104. Gingrich JR, Barrios RJ, Kattan MW, Nahm HS, Finegold MJ, Greenberg NM. Androgen-independent prostate cancer progression in the TRAMP model. Cancer Res. (1997) 57:4687-91.

105. Kasper S, Sheppard PC, Yan Y, Pettigrew N, Borowsky AD, Prins GS, et al. Development, progression, and androgen-dependence of prostate tumors in probasin-large $\mathrm{T}$ antigen transgenic mice: a model for prostate cancer. $L a b$ Invest. (1998) 78:1-15.

106. Grabowska MM, DeGraff DJ, Yu X, Jin RJ, Chen Z, Borowsky AD, et al. Mouse models of prostate cancer: picking the best model for the question. Cancer Metastasis Rev. (2014) 33:377-97. doi: 10.1007/s10555-0139487-8

107. Choi Y, Lee S, Kim K, Kim S-H, Chung Y-J, Lee C. Studying cancer immunotherapy using patient-derived xenografts. (PDXs) in humanized mice. Exp Mol Med. (2018) 50:99. doi: 10.1038/s12276-0180115-0

108. Xiao G, Wang X, Sheng J, Lu S, Yu X, Wu JD. Soluble NKG2D ligand promotes MDSC expansion and skews macrophage to the alternatively activated phenotype. J Hematol Oncol. (2015) 8:13. doi: 10.1186/s13045-015-0110-z

109. Maccalli C, Giannarelli D, Chiarucci C, Cutaia O, Giacobini G, Hendrickx W, et al. Soluble NKG2D ligands are biomarkers associated with the clinical outcome to immune checkpoint blockade therapy of metastatic melanoma patients. Oncoimmunology. (2017) 6:e1323618. doi: 10.1080/2162402X.2017.1323618

110. Kumar V, Yi Lo PH, Sawai H, Kato N, Takahashi A, Deng Z, et al. Soluble MICA and a MICA variation as possible prognostic biomarkers for HBV-induced hepatocellular carcinoma. PLoS ONE. (2012) 7:e44743. doi: 10.1371/journal.pone.0044743

111. Zhang J, Liu D, Li G, Staveley-O'Carroll KF, Graff JN, Li Z, et al. Antibody-mediated neutralization of soluble MIC significantly enhances CTLA4 blockade therapy. Sci Adv. (2017) 3:e1602133. doi: 10.1126/sciadv.16 02133

112. Lu S, Zhang J, Liu D, Li G, Staveley-O'Carroll KF, Li Z, et al. Nonblocking monoclonal antibody targeting soluble MIC revamps endogenous innate and adaptive antitumor responses and eliminates primary and metastatic tumors. Clin Cancer Res. (2015) 21:4819-30. doi: 10.1158/1078-0432.CCR15-0845

113. Wu J. Antibody targeting soluble NKG2D ligand sMIC refuels and invigorates the endogenous immune system to fight cancer. Oncoimmunology. (2016) 5:e1095434. doi: 10.1080/2162402X.2015.1 095434

114. Zhang J, Larrocha PS, Zhang B, Wainwright D, Dhar P, Wu JD. Antibody targeting tumor-derived soluble NKG2D ligand sMIC provides dual costimulation of CD8 $\mathrm{T}$ cells and enables sMIC+ tumors to respond to PD1/PD-L1 blockade therapy. J Immunother Cancer. (2019) 7:223. doi: 10.1186/s40425-019-0693-y

115. Gabrilovich DI. Myeloid-derived suppressor cells. Cancer Immunol Res. (2017) 5:3-8. doi: 10.1158/2326-6066.CIR-16-0297

116. Rodriguez PC, Ernstoff MS, Hernandez C, Atkins M, Zabaleta J, Sierra R, et al. Arginase I-producing myeloid-derived suppressor cells in renal cell carcinoma are a subpopulation of activated granulocytes. Cancer Res. (2009) 69:1553-60. doi: 10.1158/0008-5472.CAN-08-1921

117. Hart K, Byrne K, Molloy M, Usherwood E, Berwin B. IL-10 immunomodulation of myeloid cells regulates a murine model of ovarian cancer. Front Immunol. (2011) 2:29. doi: 10.3389/fimmu.201 1.00029

118. Nam S, Lee A, Lim J, Lim J-S. Analysis of the expression and regulation of PD-1 protein on the surface of myeloid-derived suppressor cells. (MDSCs). Biomol Ther. (2019) 27:63-70. doi: 10.4062/biomolther.2 018.201

119. Kumar V, Patel S, Tcyganov E, Gabrilovich DI. The nature of myeloid-derived suppressor cells in the tumor microenvironment. Trends Immunol. (2016) 37:208-220. doi: 10.1016/j.it.2016.01.004 
120. Calcinotto A, Spataro C, Zagato E, Di Mitri D, Gil V, Crespo M, et al. IL-23 secreted by myeloid cells drives castration-resistant prostate cancer. Nature. (2018) 559:363-9. doi: 10.1038/s41586-018-0266-0

121. Lu X, Horner JW, Paul E, Shang X, Troncoso P, Deng P, et al. Effective combinatorial immunotherapy for castration-resistant prostate cancer. Nature. (2017) 543:728-32. doi: 10.1038/nature21676

122. Passer BJ, Cheema T, Wu S, Wu C-L, Rabkin SD, Martuza RL. Combination of vinblastine and oncolytic herpes simplex virus vector expressing IL12 therapy increases antitumor and antiangiogenic effects in prostate cancer models. Cancer Gene Ther. (2013) 20:17-24. doi: 10.1038/cgt. 2012.75

123. Varghese S, Rabkin SD, Liu R, Nielsen PG, Ipe T, Martuza RL. Enhanced therapeutic efficacy of IL-12, but not GM-CSF, expressing oncolytic herpes simplex virus for transgenic mouse derived prostate cancers. Cancer Gene Ther. (2006) 13:253-65. doi: 10.1038/sj.cgt.7700900

124. Freedman JD, Duffy MR, Lei-Rossmann J, Muntzer A, Scott EM, Hagel J, et al. An oncolytic virus expressing a t-cell engager simultaneously targets cancer and immunosuppressive stromal cells. Cancer Res. (2018) 78:6852-65. doi: 10.1158/0008-5472.CAN-18-1750

Conflict of Interest Statement: JW holds patents of antibody targeting tumorderived soluble NKG2D ligand sMIC.

The remaining authors declare that the research was conducted in the absence of any commercial or financial relationships that could be construed as a potential conflict of interest.

Copyright (C) 2019 Boettcher, Usman, Morgans, VanderWeele, Sosman and Wu. This is an open-access article distributed under the terms of the Creative Commons Attribution License (CC BY). The use, distribution or reproduction in other forums is permitted, provided the original author(s) and the copyright owner(s) are credited and that the original publication in this journal is cited, in accordance with accepted academic practice. No use, distribution or reproduction is permitted which does not comply with these terms. 